\title{
Considering the degradation effects of amino-functional plasma polymer coatings for biomedical application
}

\author{
Dirk Hegemann ${ }^{\text {a,* }}$, Barbara Hanselmann ${ }^{\text {a }}$, Sébastien Guimond ${ }^{\mathrm{a}, 1}$, Giuseppino Fortunato ${ }^{\mathrm{a}}$, \\ Marie-Noëlle Giraud ${ }^{\mathrm{b}}$, Anne Géraldine Guex ${ }^{\mathrm{a}}$ \\ a Empa, Swiss Federal Laboratories for Materials Science and Technology, Lerchenfeldstrasse 5, 9014 St. Gallen, Switzerland \\ ${ }^{\mathrm{b}}$ Cardiology, University of Fribourg, Chemin du Musée 5, 1700 Fribourg, Switzerland
}

\begin{abstract}
Materials for biomedical applications typically involve surface engineering. Scaffolds used for tissue engineering, for example, require a surface functionalization in order to support cell growth. The deposition of functional plasma polymer coatings seems to be an attractive approach to modify substrates for biomedical applications. Possible degradation of highly functional plasma polymers and the effect of its degradation products on cell growth, however, are not yet investigated in detail. Plasma polymer formation is governed by gas phase (mainly determining the chemical composition) and surface processes (inducing cross-linking) which both influence the incorporation of amino groups in a-C: $\mathrm{H}: \mathrm{N}$ coatings deposited by $\mathrm{NH}_{3} / \mathrm{C}_{2} \mathrm{H}_{4}$ discharges. Aging is studied in air and in aqueous conditions revealing the degradation of such plasma polymers (loss in thickness and loss of amino groups). Degradation products seem to influence viability and proliferation of mouse skeletal muscle cells on electrospun poly( $\varepsilon$-caprolactone) scaffolds. Thus, possible chemical changes as a function of time or exposure to different media must be taken into account in the design of functional plasma polymer coatings for biomedical applications in order to avoid possible adverse effects on cell growth.
\end{abstract}

\section{Introduction}

Biomedical applications require special conditions for functional plasma polymer films grown at the surface of scaffolds or membranes: while adding functional groups that have to be stable in aqueous environments, changes in the mechanical and topographical properties of the substrates need to be minimized. For this purpose, both gas phase and surface processes should be well controlled during plasma polymerization. While gas phase processes are governed by the energy invested per particle (plasma chemistry), surface processes also depend on the energy flux and on the momentum transfer during film growth (plasma physics). The latter are calculated by measuring mean ion energies and ion fluxes as well as deposition rates.

Investigating hydrocarbon discharges (mainly $\mathrm{C}_{2} \mathrm{H}_{4}$ ) mixed with reactive gases such as $\mathrm{CO}_{2}$ and $\mathrm{NH}_{3}$, we found that the film density is proportional to momentum transfer by ion bombardment during film growth, whereas the functional group density (carboxylic or amino groups) scales inversely with this deposition-controlling parameter [1]. Hence, the functional group density and permanence (by crosslinking) of the a-C:H:O and a-C:H:N plasma polymers can be optimized.

Plasma activation or polymerization processes have been utilized for several years to create optimal culture substrates for adhesion

\footnotetext{
* Corresponding author.

E-mail address: dirk.hegemann@empa.ch (D. Hegemann).

1 Present address: OC Oerlikon Balzers AG, Iramali 18, 9496 Balzers, Liechtenstein.
}

dependent mammalian cells and commercially available oxygen functionalized culture dishes (TCPS) present a gold standard. Further, amino-functionalized Primaria $^{\mathrm{TM}}$ culture dishes were widely employed for cell types that grow only poorly under conventional conditions. During the last decade, plasma-functionalization has been used for the creation of enhanced biointerfaces on scaffolds for tissue engineering applications [2]. Particularly, oxygen-functional groups were demonstrated to enhance cell adhesion, proliferation and differentiation. Importantly, scaffolds must present stable functional groups, but should not release toxic degradation products upon storage or culture under aqueous conditions.

Electrospun scaffolds for tissue engineering and porous membranes for drug delivery were thus functionalized using plasma polymerization with the aim to maintain their submicrometer 3D architecture and their mechanical properties. Ultrathin plasma polymer layers $(<10 \mathrm{~nm})$ were deposited, since thicker coatings were found to affect substrate stiffness and degradability $[3,4]$. While $\mathrm{CO}_{2} / \mathrm{C}_{2} \mathrm{H}_{4}$ gas discharges have already been proven to support cell growth on electrospun poly( $\varepsilon$-caprolactone) (PCL) scaffolds used for tissue engineering [5], we now investigate the ability of $\mathrm{NH}_{3} / \mathrm{C}_{2} \mathrm{H}_{4}$ gas discharges for the same purpose. Such amino-functional plasma polymers were recently used as adhesion promoting layers in fiber-reinforced composites as well as on membranes to chemically attach thermoresponsive poly(oligo(ethylene glycol) methacrylate) (pOEGMA) copolymers forming brushes [6,7]. After the chemical reaction the amino-functionalized plasma layers were found to be permanent [8]. 
Plasma polymer films with nitrogen-functional groups (a-C:H:N) are also frequently used for biomedical applications [2,3,9,10]. Degradation effects such as oxidation and leaching of low molecular weight fragments that are known to occur for amino-functional plasma polymers, however, require special handling [9,11-16]. Prior to cell attachment $\mathrm{a}-\mathrm{C}: \mathrm{H}: \mathrm{N}$-coated samples are therefore stored in air for several weeks, thermally treated (in vacuum) and/or washed with solvents, while the media is frequently exchanged during cell growth [17-19]. We could thus demonstrate that cell growth of mouse fibroblasts (cell line 3T3) is supported on amino-functionalized plasma polymer-coated Petri dishes after 1 day of pre-incubation in water [20]. In the current study, however, we investigate the effect of plasma polymer layer/coating degradation on cell growth of mouse skeletal muscle cells (cell line C2C12) cultured on a biodegradable, electrospun PCL scaffold without preincubation or further surface treatment.

\section{Experimental}

\subsection{Plasma processing}

Amino-functional plasma polymers were deposited from $\mathrm{NH}_{3} / \mathrm{C}_{2} \mathrm{H}_{4}$ discharges using two different (almost symmetric) plasma reactors with $13.56 \mathrm{MHz}$ radiofrequency (RF) excitation [21]. A lab-scale batch reactor with an electrode size of $700 \mathrm{~cm}^{2}$ and a pilot-scale web coater with an electrode size of $12,000 \mathrm{~cm}^{2}$ were used. RF was capacitively coupled to the substrate bearing electrode. The range of power input $W$ per monomer gas flow rate $F_{m}$ was kept between 60 and $350 \mathrm{~J} \mathrm{~cm}^{-3}$ for all experiments, while the $\mathrm{NH}_{3} / \mathrm{C}_{2} \mathrm{H}_{4}$ gas flow ratio was varied between 0.8 and 4 and the pressure was fixed at $10 \mathrm{~Pa}$. The deposited mass was measured by weighing thin glass slide substrates right before and after deposition. Electric characteristics of the discharge were observed by a V/I probe (ENI Model 1065) and electron densities were measured using microwave interferometry (JE PlasmaConsult MWI 2650) showing a linear behavior with power input [21]. Chemical composition was examined by XPS surface analysis (PHI 5600 LS), also using derivatization with 4-(trifluoromethyl)benzaldehyde (TFBA) vapor to determine the amino group density with respect to the carbon concentration $\left(\mathrm{NH}_{2} / \mathrm{C}\right)$ [22]. Samples were stored in controlled environment $\left(21{ }^{\circ} \mathrm{C}, 65 \%\right.$ relative humidity $\left.(\mathrm{RH})\right)$ for 20 days and in deionized water for $2 \mathrm{~h}$.

\subsection{Scaffold production and characterization}

Nanofibrous scaffolds were produced by electrospinning on a home-built setup. Briefly, a 15\% w/v polymer solution of PCL in acetic acid/pyridine (all from Sigma-Aldrich, Switzerland) was introduced in an electrostatic field and processed at an electric field strength of $1 \mathrm{kV} \mathrm{cm}^{-1}$ and $30 \mu \mathrm{L} \mathrm{min}^{-1}$ flow rate [5,23]. As-spun substrates were plasma functionalized in the lab-scale batch reactor. Plasma process parameters were set to an energy input of $110 \mathrm{~J} \mathrm{~cm}^{-3}$, an $\mathrm{NH}_{3} / \mathrm{C}_{2} \mathrm{H}_{4}$ ratio of $2: 1$, and a process duration of $20 \mathrm{~min}$ at a pressure of $10 \mathrm{~Pa}$. Chemical surface composition was assessed by XPS, fiber morphology by scanning electron microscopy (SEM, Hitachi, Canada).

\subsection{Cell culture and analysis}

All experiments were accomplished on $\mathrm{NH}_{3} / \mathrm{C}_{2} \mathrm{H}_{4}$ plasma functionalized scaffolds (indicated as 'amino'), as-spun PCL scaffolds ('ctrl.') and tissue treated culture dishes ('TCPS'; TPP Omnilab, Switzerland). Different intervals between plasma coating and cell seeding were considered (freshly prepared or stored/aged for 9 months in air) without pre-incubation or washing. Cell seeding and culture on the scaffolds were accomplished as described in detail by Guex et al. [24]. Briefly, $6 \mathrm{~mm}$ diameter substrates were cut and sterilized under UV. Murine skeletal myoblasts (C2C12, ATCC, Manassas, USA) were seeded at a density of $0.2510^{6}$ cells per patch. Constructs were cultured under standard conditions in a humidified incubator at $37{ }^{\circ} \mathrm{C}$ and $5 \% \mathrm{CO}_{2}$. Myotube differentiation was initiated 7 days post seeding with a serum-deprived culture medium for an additional period of 14 days.

Cells were assessed for viability and substrate toxicity as previously reported [5]. In short, substrate toxicity and resulting cell death were monitored by lactate dehydrogenase (LDH) release into the culture medium on days 3, 5 and 7 (LDH toxicity test, Sigma-Aldrich, Switzerland); whereas cell viability was assessed by a 3-(4,5-dimethylthiazol-2-yl)2,5-diphenyltetrazolium bromide test, $48 \mathrm{~h}$ after seeding (MTT, Sigma-Aldrich, Switzerland). Cell number was quantified on days 3, 5 and 7 post seeding using a commercially available cell proliferation assay kit (CyQuant; Invitrogen, USA). Myoblast differentiation and fusion into myotubes were assessed by immunohistochemistry and positive desmin staining (anti-desmin antibody, Abd Serotec, USA; and EnVision System-HRP Kit, Dako, USA).

\section{Results and discussion}

The deposition of plasma polymers is both governed by gas phase and surface processes, where the latter is different on flat and 3D structured substrates due to the interaction with energetic particles (mainly ions). While the ions incident on a 3D structured material mainly reach surfaces in the line of sight, the film-forming species as produced by gas phase processes are able to penetrate deeper into the material. The amino-functional plasma polymer is thus deposited under rather mild conditions on the electrospun PCL substrate, i.e. the deposition is mainly governed by plasma-chemical reactions. Therefore, (flat) samples used for surface analytics (Si wafers) were coated in the web coater which enables a low energy flux (product of mean ion energy and ion flux) to the surface, while the fibrous PCL substrates were treated in the smaller batch reactor. Both electron temperature $T_{e}$ and electron density $n_{e}$ are found to decrease with the reactor size, since electrons are kept for a longer time within the plasma volume [25]. Ion-induced etching effects that strongly reduce deposition rate are thus only found for high $\mathrm{NH}_{3} / \mathrm{C}_{2} \mathrm{H}_{4}$ ratios, where a high energy density due to the overall low deposition rates is observed $[21,26]$. Note that energy density is defined as energy flux per deposition rate, i.e. the flux of depositing species [27]. Mass deposition rates for an $\mathrm{NH}_{3} / \mathrm{C}_{2} \mathrm{H}_{4}$ gas ratio between 0.8 and 2, on the other hand, follow an Arrhenius behavior as a function of the energy input $W / F_{m}$ (power input per monomer gas flow rate), which is indicative of a predominant plasma-chemical reaction pathway with an activation barrier $E_{a}$ :

$\frac{R_{m}}{F_{m}}=G \exp \left(-\frac{E_{a}}{W / F_{m}}\right)$,

where $G$ is a reactor and process dependent factor related to the conversion of monomer into film growth [28]. Deposition on the PCL scaffolds (by choosing an $\mathrm{NH}_{3} / \mathrm{C}_{2} \mathrm{H}_{4}$ ratio of 2) was performed in a smaller batch reactor that, nevertheless, enabled the same plasma-chemical reaction pathway [21]. The used range of $W / F_{m}$ was kept above $E_{a}$ as obtained for $\mathrm{NH}_{3} / \mathrm{C}_{2} \mathrm{H}_{4}$ discharges in previous works. Following Eq. (1) the deposition rate thus increases slowly with power.

The stability and functional group density of the amino-functional plasma polymers were examined with respect to the momentum transfer during film growth, since we could recently show that cross-linking and densification scale with momentum transfer as given by

$\pi_{\text {surf }}=\frac{n_{0} \sqrt{V_{s h}}}{R} f\left(T_{e}, p\right)$,

where $n_{0}$ is the plasma density (which equals $n_{e}$ for electropositive discharges), $V_{s h}$ is the sheath voltage in front of the sample, $R$ is the (atomic) deposition rate, and $f$ is a factor that depends on electron temperature $T_{e}$ and pressure $p[1,28]$. Since the variation of $T_{e}$ with power input can be neglected and $p$ was kept constant at $10 \mathrm{~Pa}$, the factor $f$ is actually a 


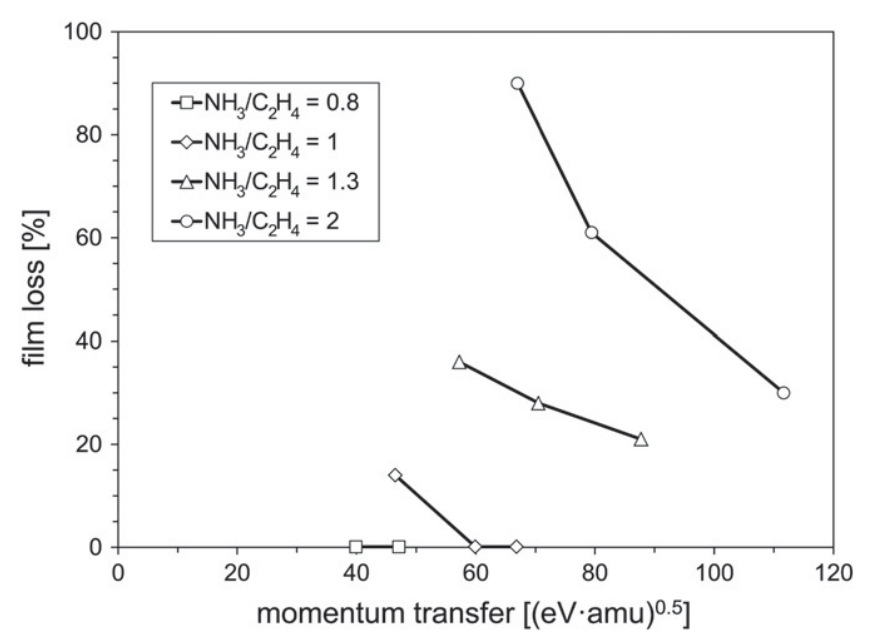

Fig. 1. Film loss of a-C:H:N plasma polymers stored for $2 \mathrm{~h}$ in water. While the plasma polymers become less stable with an increasing $\mathrm{NH}_{3} / \mathrm{C}_{2} \mathrm{H}_{4}$ ratio, enhanced momentum transfer improves stability by cross-linking.

constant for the used experimental conditions. The momentum transfer thus increases with power input (for $W / F_{m}$ above $E_{a}$ ).

At first, plasma-coated samples ( $\mathrm{Si}$ wafers) were stored for $2 \mathrm{~h}$ in deionized water revealing film loss depending on $\mathrm{NH}_{3} / \mathrm{C}_{2} \mathrm{H}_{4}$ gas ratio and momentum transfer (Fig. 1). Film loss is thus closely related to the cross-linking density of the a-C:H:N plasma polymers [29,30]. Stable amino-functional plasma polymers could only be observed for gas ratios up to 1 , while higher ratios resulted in substantial film loss. In any case, a thin (few nanometer thick) $\mathrm{N}$-functional hydrocarbon layer remained on the substrate, probably due to reduced deposition rates at the initial film growth and higher cross-linking (considering the energy density during film growth) [26,31].

Next, the chemical composition of the plasma polymers was compared before and after aging conditions (Fig. 2). First of all, the chemical (elemental) composition is independent of power input and also independent of the energetic conditions (momentum transfer) during film growth. The incorporation of nitrogen only scales with the $\mathrm{NH}_{3} / \mathrm{C}_{2} \mathrm{H}_{4}$ ratio, agreeing well with the assumption of a predominant plasma-chemical reaction pathway following an Arrhenius behavior. Therefore, we can expect the same elemental composition on the scaffolds, i.e. on a complex 3D structure. After aging, all films revealed a

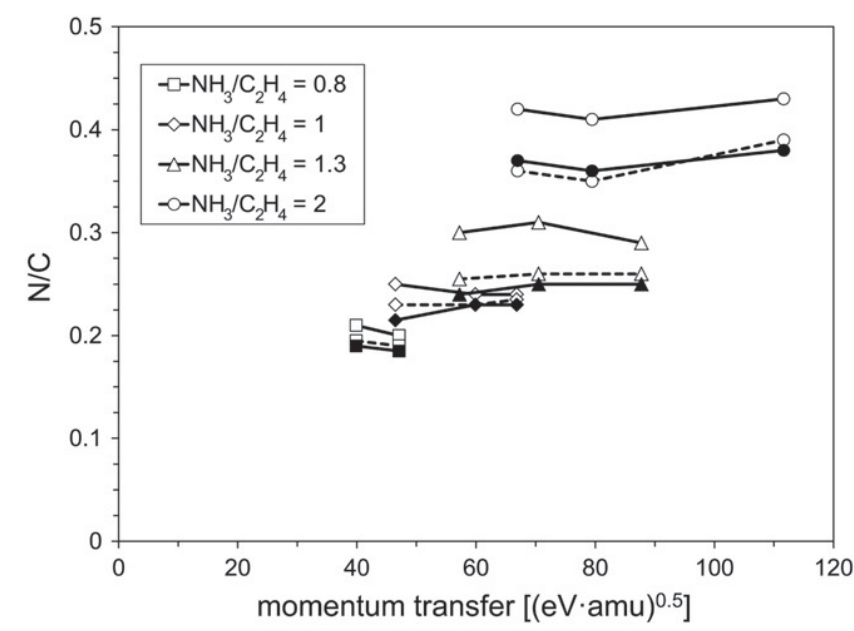

Fig. 2. Elemental composition ( $\mathrm{N} / \mathrm{C}$ ratio) after deposition (open symbols connected by solid lines), after storage in air for 20 days (open symbols connected by dashed lines) and after storage in water for $2 \mathrm{~h}$ (closed symbols connected by solid lines). $\mathrm{N} / \mathrm{C}$ decreases stronger with an increasing $\mathrm{NH}_{3} / \mathrm{C}_{2} \mathrm{H}_{4}$ ratio independent of aging in water or air. reduction in the nitrogen concentration $(\mathrm{N} / \mathrm{C})$, which becomes more pronounced for higher $\mathrm{NH}_{3} / \mathrm{C}_{2} \mathrm{H}_{4}$ gas ratios. The oxygen content (at the surface) increased from $\mathrm{O} / \mathrm{C}=0.07 \pm 0.02$ to $\mathrm{O} / \mathrm{C}=0.14 \pm$ 0.04 after degradation in humid air or deionized water without showing a trend with the deposition parameters. Both storage conditions (humid air and water) yield a comparable aging. The chemical changes were found to saturate after about 20 days of aging in air $\left(21^{\circ} \mathrm{C}, 65 \% \mathrm{RH}\right)$, which agrees well with findings by other groups [16]. Using dry air (or nitrogen) slows down the degradation mechanism, revealing the influence of humidity $[11,16]$.

The density of primary amino groups shows a different behavior (Fig. 3). Again the $\mathrm{NH}_{2} / \mathrm{C}$ ratio scales with the $\mathrm{NH}_{3} / \mathrm{C}_{2} \mathrm{H}_{4}$ gas ratio in the discharge, but also with the momentum transfer at the growing film surface indicating cross-linking reactions yielding a loss in functionality. After aging, however, the $\mathrm{NH}_{2} / \mathrm{C}$ ratio was found to show the same (lower) level of around 2\% independent of storage in air or water. Plasma polymers containing primary amino groups are known to show aging effects, i.e. oxidation reactions yielding the formation of amides (among other functional groups) $[11,13,14]$. Immersion in water results in weight loss and removal of nitrogen groups from the residual deposit, e.g., by hydrolysis of imine groups. The oligomeric parts of the films are released due to degradation accompanied by pore formation in the remaining films [12]. This degradation occurs already within a few hours of storage in water and leaves the cross-linked portion of the plasma polymer on the substrate $[12,14,26]$.

From these results, deposition conditions at an $\mathrm{NH}_{3} / \mathrm{C}_{2} \mathrm{H}_{4}$ gas ratio of 2 were selected to investigate cell growth of mouse skeletal muscle cells on electrospun poly( $\varepsilon$-caprolactone) scaffolds, in order to examine the influence of rapid film degradation within aqueous environments of initially amino-rich $\left(\mathrm{NH}_{2} / \mathrm{C}\right.$ ratio of 6-9\%) plasma layers.

Optimized electrospinning parameters allowed for the production of homogenously assembled fibers in the sub-micrometer range (mean diameter of $237 \pm 98 \mathrm{~nm}$ ). XPS analysis confirmed the deposition of a nitrogen-functional hydrocarbon coating (Table 1). Comparable to results on Si wafers, nitrogen functional groups on electrospun PCL fibers undergo oxidation in air, indicated by the increased oxygen content and altered $\mathrm{N} / \mathrm{C}$ ratio 9 months after processing (substrates stored at RT in air). Note that the XPS measurement directly on the fibers also records the PCL substrate due to the nanoscaled plasma polymer layer, thus explaining the overall higher $\mathrm{C}$ and $\mathrm{O}$ contents.

MTT staining, performed $48 \mathrm{~h}$ post seeding, indicates reduced cell viability on freshly amino-functionalized scaffolds, compared to control groups on as-spun scaffolds or TCPS (Fig. 4). Interestingly, cell viability is

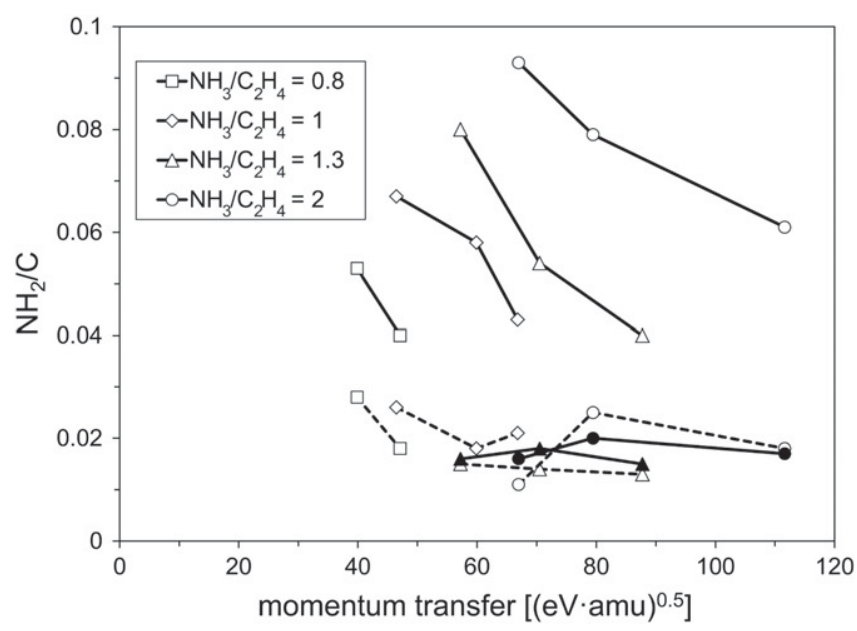

Fig. 3. Functional group density $\left(\mathrm{NH}_{2} / \mathrm{C}\right.$ ratio) after deposition (open symbols connected by solid lines), after storage in air for 20 days (open symbols connected by dashed lines) and after storage in water for $2 \mathrm{~h}$ (closed symbols connected by solid lines). Enhanced momentum transfer yields a decrease in functionality due to cross-linking. After aging a comparable amount of amino groups remains independent of the actual treatment. 
Table 1

Chemical surface composition on electrospun PCL fibers, assessed by XPS on freshly prepared plasma polymer films and after long-term storage in air.

\begin{tabular}{|c|c|c|c|c|c|c|c|c|}
\hline & \multicolumn{8}{|c|}{ Average elemental composition in at\% } \\
\hline & \multicolumn{4}{|c|}{ Directly after processing } & \multicolumn{4}{|c|}{9 months post processing } \\
\hline & C & 0 & $\mathrm{~N}$ & $\mathrm{~N} / \mathrm{C}$ & C & 0 & $\mathrm{~N}$ & $\mathrm{~N} / \mathrm{C}$ \\
\hline Pure & 77.4 & 22.6 & 0 & 0 & & & & \\
\hline Plasma-coated & 74.2 & 9.4 & 18.1 & 0.24 & 76.5 & 11.7 & 11.8 & 0.15 \\
\hline
\end{tabular}

enhanced on amino-functionalized scaffolds that were stored in air at RT for 9 months.

In line with reduced cell viability, LDH release into the culture medium is increased on amino-functionalized scaffolds (Fig. 5). An initial burst release is monitored on day 3 , being reduced on days 5 and 7 . A low LDH release is indicative for either very low cell mortality, or a low cell number. On amino-functionalized scaffolds, the cell number slightly decreases over time (Fig. 6), thereby releasing lower LDH amount than on control scaffolds. Thereon, LDH release remains constant throughout the culture period. A relatively high LDH release on TCPS corroborates the high cell number and consequently enhanced cell mortality under highly confluent culture conditions.

Light microscopy images underpin these findings of low cell viability and cell number on freshly amino functionalized scaffolds. Myoblasts display a round, pheno-atypical morphology (Fig. 7). The round morphology further indicates reduced cell adhesion to the substrates and consequential cell death. Such effects were not observed on untreated or a-C:H:O plasma-coated PCL scaffolds [5,23]. Interestingly, on amino-functionalized as well as on pure substrates, myoblasts differentiate into multinucleated myotubes after prolonged cell culture and regular media exchange.

These results of distinct cell response to aged surface coatings lie in agreement with the measured plasma layer stability. We therefore hypothesize that long-term aged scaffolds present more stable nitrogen (amino) groups that result in enhanced cell viability and reduced LDH release.

These findings agree well with results obtained by other groups showing that oxidation processes support stabilization of the a-C:H:N plasma polymer starting several days after deposition $[11,12,16]$. Some studies, however, report enhanced adhesion and spreading within hours post seeding of mammalian cells on amine or amide containing

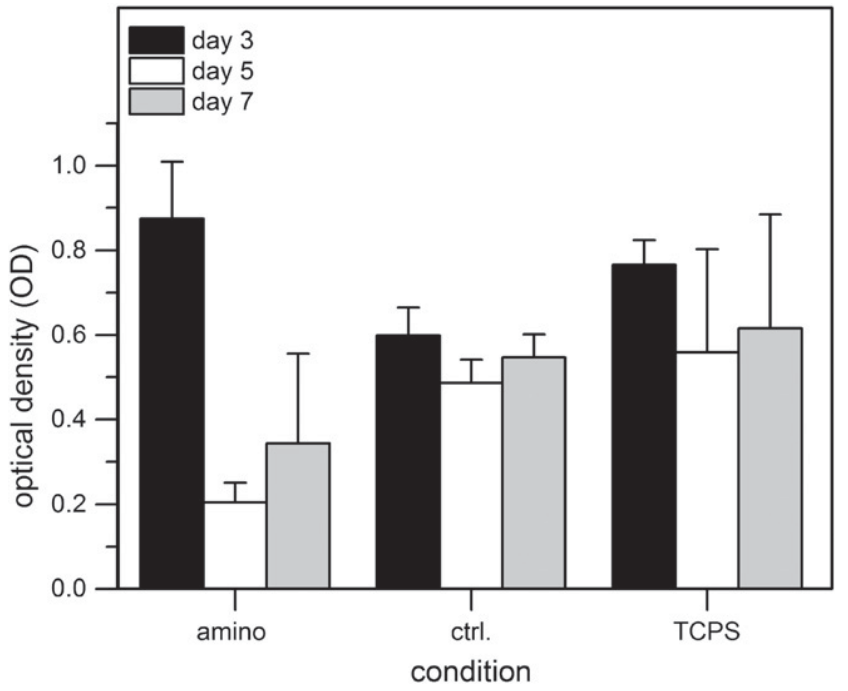

Fig. 5. LDH release assessed over a culture period of 7 days. $\mathrm{LDH}$ release, indicative for cell death, is enhanced on freshly amino-functionalized scaffolds on day 3. The high LDH release on TCPS is due to an enhanced proliferation and increased cell number; leading to over-confluent cell culture.

surface coatings $[3,10,32]$. While those studies did not mention the storage conditions prior to cell seeding, the positive results might also be explained by a lower initial $\mathrm{NH}_{2} / \mathrm{C}$ ratio $(<1 \%$ in [32] and $2-4 \%$ in [11]), which is close to our finding of stabilized films at around $2 \%$ amino groups.

The examined freshly prepared, initially amino-rich plasma polymers were also found to support cell growth after pre-incubation or exchange of the culture media [20]. Enhanced cell viability and differentiation into myotubes after an expansion of the culture period of several days/weeks (requiring exchange of the medium) both underpin the hypothesis of fast degradation of the a-C:H:N plasma polymer that forms a stable layer after an initial decomposition. To this end, we hypothesize that the small amount of viable cells that remains on the scaffold would further differentiate into myotubes, once the degradation products have been removed and the plasma polymer surface is stabilized.

Leaching of amino-rich oligomers from freshly prepared a-C:H:N plasma films into the culture medium might lead to an occurrence of an adverse reaction on cells. Decomposed substances containing
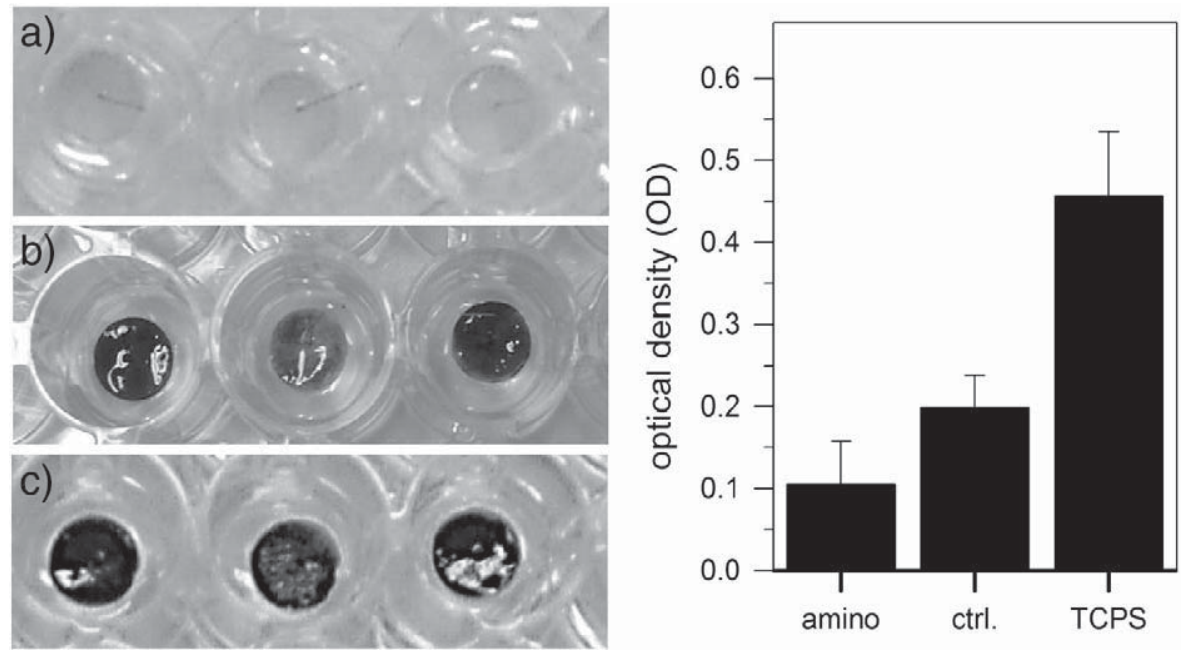

Fig. 4. Photographs and spectrophotometrical assessment of MTT staining $48 \mathrm{~h}$ post seeding. a) Freshly prepared amino-functionalized scaffolds, b) amino-functionalized scaffolds after long-term storage in air, c) control group, no plasma functionalization. A deep, dark color indicates viable cells, whereas the light colored scaffolds in a) indicate reduced cell viability. Spectrophotometrical quantification of MTT was accomplished on freshly prepared amino functionalized scaffolds and control groups. 


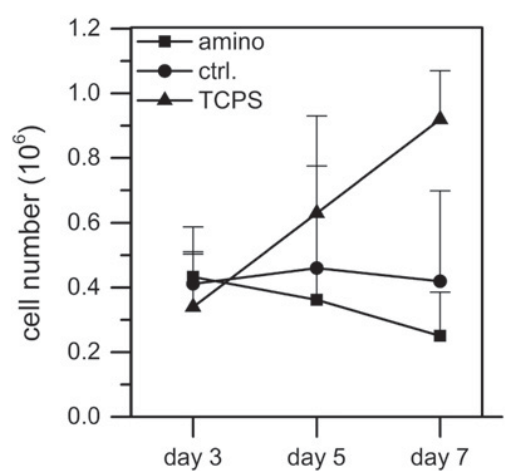

Fig. 6. Cell number, assessed by CyQuant, over a culture period of 7 days. On TCPS, the cells present a high proliferation rate, whereas on amino-functionalized scaffolds, cell number decreases over time, presenting even lower cell proliferation than on pure PCL substrates.

polyamines, i.e. an organic compound with terminal amino groups, are known to interact on cellular signaling pathways, thereby modifying cell proliferation or cell death and apoptosis [33,34]. The diverse cellular response and underlying mechanisms are not fully understood yet and leachable molecules from functionalized layers are therefore generally undesired. Degradation products are, however, removed by exchange of the medium leaving a stabilized functional surface (with reduced $\mathrm{NH}_{2} / \mathrm{C}$ content).

In summary, it can be stated that a-C:H:N films deposited with an $\mathrm{NH}_{3} / \mathrm{C}_{2} \mathrm{H}_{4}$ ratio of 2:1 (and thus a high initial $\mathrm{NH}_{2} / \mathrm{C}$ ratio) on electrospun membranes do not present stable surfaces suitable for the used cell culture (murine skeletal myoblasts). Cell viability strongly depends on the aging effects of the substrates and the plasma layer. Although the underlying processes of cell morphology and differentiation on aminofunctionalized plasma coatings remain open, we would like to emphasize on the low stability of highly amino-functional layers and the potential risk of consequential heterogeneous results in cell culture. Reproducible results highly depend on the previous history of the plasma coated substrates. Stating precise details on culture protocols, including for instance washing or pre-incubation in media, is thus of paramount importance for cell culture studies.

\section{Conclusion}

Amino-functional plasma polymers can be deposited on flat as well as on 3D structured substrates using $\mathrm{NH}_{3} / \mathrm{C}_{2} \mathrm{H}_{4}$ discharges as long as the deposition is mainly governed by plasma chemical processes, i.e. avoiding strong etching effects by ion bombardment. Therefore, the deposition on electrospun PCL scaffolds in a lab-scale reactor could be compared to the deposition on flat substrates in a much larger web coater, in which case rather mild plasma conditions were used. Increased amounts of nitrogen incorporation can be achieved by increasing the $\mathrm{NH}_{3} / \mathrm{C}_{2} \mathrm{H}_{4}$ ratio in the plasma. The number of incorporated primary amino groups can also be raised with the $\mathrm{NH}_{3} / \mathrm{C}_{2} \mathrm{H}_{4}$ ratio, but was found to be reduced due to momentum transfer and densification (cross-linking) during film growth. Increasing the $\mathrm{NH}_{3} / \mathrm{C}_{2} \mathrm{H}_{4}$ ratio, however, induces strong aging effects and degradation of the plasma polymer coatings. To examine the impact of such effects on cell growth, films deposited at an $\mathrm{NH}_{3} / \mathrm{C}_{2} \mathrm{H}_{4}$ ratio of 2 were used. Freshly prepared, amino-rich films were found to induce cell death of mouse skeletal muscle cells, most likely due to released nitrogen-containing oligomers. After removal of the media containing such degradation products, the cells could recover.

More permanent a-C:H:N plasma polymers showing no film loss or reduced $\mathrm{N} / \mathrm{C}$ after aging can be achieved with a lower $\mathrm{NH}_{3} / \mathrm{C}_{2} \mathrm{H}_{4}$ ratio (around 1) yielding a lower initial primary amino group density $\left(\mathrm{NH}_{2} /\right.$ C ratio). Interestingly, all examined coatings end up at an $\mathrm{NH}_{2} / \mathrm{C}$ value of about $2 \%$ after storage in air or in water which represents suitable conditions for cell growth. Possible adverse effects on cell reaction as caused by leaching of oligomers can thus be avoided by selecting proper plasma conditions.

In summary, advanced plasma polymer coatings for biomedical applications such as support of cell growth require the thorough investigation of film properties within the biological environment, while common film characterization might be insufficient or even misleading. In any case, amino-functionalized plasma polymers are suitable for biomedical applications after pre-incubation (e.g. in water). Similar suitable starting conditions might also be obtained by storage of about 20 days in (humid) air. The actual plasma conditions are found to be less sensitive, i.e. even different energetic conditions during film growth a)

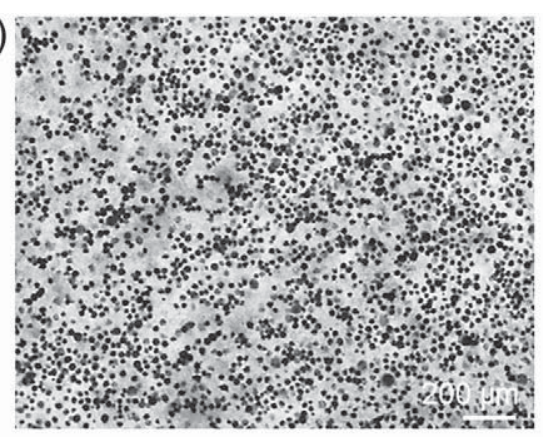

C)

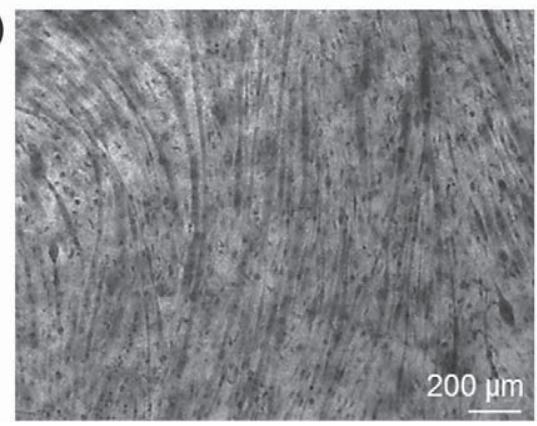

b)

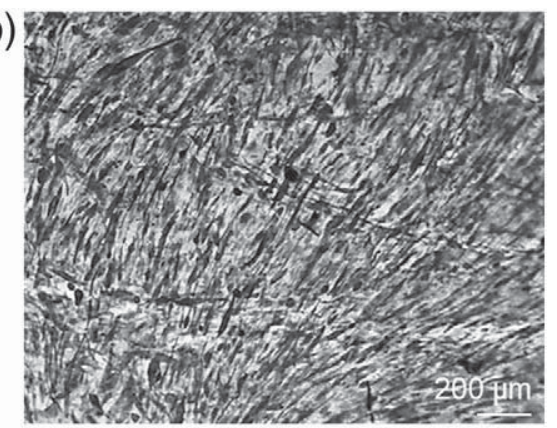

d)

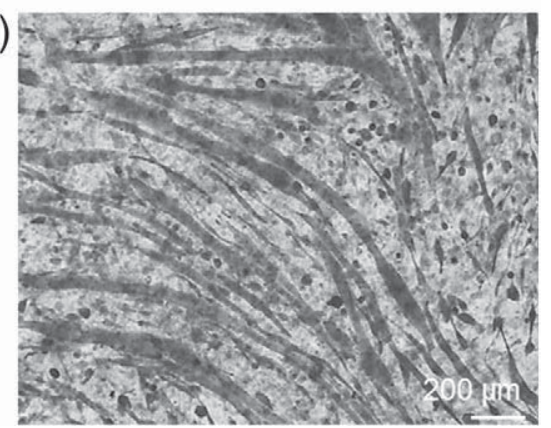

Fig. 7. Light microscopy images of desmin ${ }^{(+)}$-stained myoblasts 7 days post seeding (a, b) and myotubes 21 days post seeding (c,d) on amino-functionalized scaffolds (a,c) and control groups (b,d). C2C12 on amino-functionalized scaffolds display a round morphology, whereas in b) C2C12 display a typical, elongated morphology. On both substrates, myoblast differentiated into multinucleated myotubes after prolonged culture (21 days) and regular exchange of culture media (c,d). Scale bar: $200 \mu \mathrm{m}$. 
result in comparable coatings (after aging). 3D structured substrates can thus be functionalized and stored using plasma polymerization processes.

\section{Acknowledgments}

A.G.G. gratefully acknowledges the financial support of the Swiss National Science Foundation (SNF grant no. 122334) as well as the Clinic of Cardiovascular Surgery, University Hospital Bern, Switzerland, for support in the cell studies.

\section{References}

[1] D. Hegemann, E. Körner, N. Blanchard, M. Drabik, S. Guimond, Appl. Phys. Lett. 101 (2012) 211603.

[2] K.S. Siow, L. Britcher, S. Kumar, H.J. Griesser, Plasma Process. Polym. 3 (2006) 392.

[3] R. Wyrwa, B. Finke, H. Rebl, N. Mischner, M. Quaas, J. Schäfer, C. Bergemann, J.B. Nebe, K. Schröder, K.D. Weltmann, M. Schnabelrauch, Adv. Biomater. 13 (2011) B165.

[4] K. Golib-Vainshtein, O. Girshevitz, C.N. Sukenik, D. Barlam, E. Kalfon-Cohen, S.R. Cohen, J. Phys. Chem. 117 (2013) 22232.

[5] A.G. Guex, F.M. Kocher, G. Fortunato, E. Körner, D. Hegemann, T.P. Carrel, H.T. Tevaearai, M.N. Giraud, Acta Biomater. 8 (2012) 1481.

[6] N. Graupner, K. Albrecht, D. Hegemann, J. Müssig, J. Appl. Polym. Sci. 128 (2013) 4378.

[7] F. Teixeira Jr., A.M. Popa, S. Guimond, D. Hegemann, R.M. Rossi, J. Appl. Polym. Sci. 129 (2013) 636.

[8] M.M. Hossain, A.S. Herrmann, D. Hegemann, Plasma Process. Polym. 4 (2007) 135

[9] R. Förch, Z. Zhang, W. Knoll, Plasma Process. Polym. 2 (2005) 351.

[10] S. Lerouge, A. Major, P.L. Girault-Lauriault, M.A. Raymond, P. Laplante, G. Soulez, F. Mwale, M.R. Wertheimer, M.J. Hebert, Biomaterials 28 (2007) 1209.

[11] T.R. Gengenbach, R.C. Chatelier, H.J. Griesser, Surf. Interface Anal. 24 (1996) 271.

[12] K. Vasilev, L. Britcher, A. Casanal, H.J. Griesser, J. Phys. Chem. B 112 (2008) 10915.

[13] B. Finke, K. Schröder, A. Ohl, Plasma Process. Polym. 6 (2009) S70.
[14] J.C. Ruiz, A. St-Georges-Robillard, C. Theresy, S. Lerouge, M.R. Wertheimer, Plasma Process. Polym. 7 (2010) 737.

[15] A. Artemenko, O. Kylian, J. Kousal, A. Choukourov, O. Polonskyi, D. Slavinska, H. Biederman, Surf. Coat. Technol. 205 (2011) S529.

[16] P.L. Girard-Lauriault, P.M. Dietrich, T. Gross, T. Wirth, W.E.S. Unger, Plasma Process. Polym. 10 (2013) 388

[17] H.J. Griesser, R.C. Chatelier, T.R. Gengenbach, G. Johnson, J.G. Steele, J. Biomater. Sci., Polym. Ed. 5 (1994) 531-554.

[18] C.H. Bamford, K.G. Al-Lamee, Polymer 37 (1996) 4885

[19] Z. Yang, J. Wang, R. Luo, X. Li, S. Chen, H. Sun, N. Huang, Plasma Process. Polym. 8 (2011) 850.

[20] S. Lischer, E. Körner, D.J. Balazs, D. Shen, P. Wick, K. Grieder, D. Haas, M. Heuberger D. Hegemann, J. R. Soc. Interface. 8 (2011) 1019

[21] S. Guimond, U. Schütz, B. Hanselmann, E. Körner, D. Hegemann, Surf. Coat. Technol. 205 (2011) S447.

[22] P. Favia, M.V. Stendardo, R. d'Agostino, Plasmas Polym. 1 (1996) 91.

[23] A.G. Guex, D.L. Birrer, G. Fortunato, H.T. Tevaearai, M.N. Giraud, Biomed. Mater. 8 (2013) 021001.

[24] A.G. Guex, G. Fortunato, D. Hegemann, H.T. Tevaearai, M.N. Giraud, in: K. Turksen (Ed.), Stem Cell Nanotechnology: Methods and Protocols (Methods in Molecular Biology), Humana Press, 2013, p. 180.

[25] A. von Engel, Electric Plasmas: Their Nature and Uses, Taylor \& Francis, London, 1983.

[26] D. Hegemann, B. Hanselmann, N. Blanchard, M. Amberg, Contrib. Plasma Phys. 54 (2014) 162.

[27] D. Hegemann, U. Schütz, E. Körner, Plasma Process. Polym. 8 (2011) 689.

[28] D. Hegemann, J. Phys. D. Appl. Phys. 46 (2013) 205204.

[29] Z. Zhang, Q. Shen, W. Knoll, R. Förch, Surf. Coat. Technol. 174-175 (2003) 588.

[30] L. Denis, D. Thiry, D. Cossement, P. Gerbaux, F. Brusciotti, I. Van De Keere, V. Goossens, H. Terryn, M. Hecq, R. Snyders, Prog. Org. Coat. 70 (2011) 134.

[31] K. Vasilev, A. Michelmore, P. Martinek, J. Chan, V. Sah, H. Griesser, R.D. Short, Plasma Process. Polym. 7 (2010) 824

[32] D. Mangindaan, W.H. Kuo, C.C. Chang, S.L. Wang, H.C. Liu, M.J. Wang, Surf. Coat Technol. 206 (2011) 1299.

[33] T. Thomas, T.J. Thomas, Cell. Mol. Life Sci. 58 (2001) 244.

[34] R. Hochreiter, T.M. Weiger, S. Colombatto, T. Langer, T.J. Thomas, C. Cabella, W. Heidegger, M.A. Grillo, A. Hermann, N. Schmied, Arch. Pharmacol. 361 (2000) 235. 